\title{
EDUCAÇÃO FÍSICA, AMBIENTAL E INCLUSIVA: UM RELATO DE EXPERIÊNCIA INTERDISCIPLINAR NO DESENVOLVIMENTO E APRESENTAÇÃO DE JOGOS SENSORIAIS ADAPTADOS A UMA ESTUDANTE COM DEFICIÊNCIA VISUAL
}

\author{
João Paulo dos Santos Oliveira*, Rafaela Dias Melo \\ *E-mail: joaoliveira1488@gmail.com \\ Instituto Federal de Educação, Científica e Tecnologia de Pernambuco, Brasil \\ DOI: $10.15628 /$ rbept.2020.8987 \\ Artigo submetido em set/2019 e aceito em fev/2020
}

\begin{abstract}
RESUMO
No ano de 2017, o Campus Garanhuns do Instituto Federal de Pernambuco recebeu, pela primeira vez, uma estudante com deficiência visual em seu Curso Técnico em Meio Ambiente integrado ao Ensino Médio. Esta realidade nos trouxe o desejo de superar barreiras atitudinais e estruturais que pudessem trazer dificuldades à aprendizagem da estudante. Esta iniciativa culminou com o desenvolvimento de estratégias metodológicas de natureza interdisciplinar, apresentadas neste texto a partir do relato de uma experiência interdisciplinar que aproximou as disciplinas Educação Física e Educação Ambiental através do conteúdo Jogos de Tabuleiro. Concluímos que a abordagem interdisciplinar dos temas foi uma experiência exitosa, por permitir oportunizar a ampliação do repertório de conhecimentos dos estudantes, acerca da educação ambiental no contexto inclusivo.
\end{abstract}

Palavras-Chave: Educação Física. Educação Ambiental. Deficiência Visual. Inclusão.

\section{PHYSICAL, ENVIRONMENTAL AND INCLUSIVE EDUCATION: AN ACCOUNT OF INTERDISCIPLINARY EXPERIENCE IN THE DEVELOPMENT AND PRESENTATION OF SENSORY GAMES ADAPTED TO A STUDENT WITH VISUAL IMPAIRMENT}

\begin{abstract}
In 2017, the Garanhuns Campus of the Federal Institute of Pernambuco received, for the first time, a visually impaired student in its Technical Course in Environment integrated to High School. This reality brought us the desire to overcome attitudinal and structural barriers that could bring difficulties to the student's learning. This initiative culminated in the development of methodological strategies of an interdisciplinary nature, presented in this text from the report of an interdisciplinary experience that approached the Physical Education and Environmental Education disciplines through the Board Games content. We conclude that the interdisciplinary approach of the themes was a successful experience, as it allowed us to expand the students' knowledge repertoire about environmental education in the inclusive context.

Keywords: Physical Education. Environmental education. Visual impairment. Inclusion.
\end{abstract}




\section{INTRODUÇÃO}

Do ponto de vista das políticas educacionais, nas últimas décadas, anos o Ensino Médio (EM) tem se constituído como um importante desafio ao Estado Brasileiro. Empreendendo uma análise que se atenha - sem desconsiderar a existência de outras diversas perspectivas e caminhos possíveis - às dimensões identitária e social, podemos constatar que, em ambos os casos, tal desafio se estabelece no enfrentamento e superação de crises.

O desafio inerente à primeira dimensão relaciona-se ao caráter propedêutico, atribuído à escola e o consequente rebatimento que políticas educacionais historicamente voltadas à formação para uma lógica de mercado (FREITAS, 2018) - seja por um viés tecnicista (SAVIANI, 2011), seja mediante aproximação a uma lógica situada pelas competências, de matriz neoliberal imprime ao imaginário dos estudantes sobre o papel da escola em sua formação.

Noutro ponto, reconhecemos que, para além da necessária universalização do EM a partir de parâmetros de qualidade e equidade, da promoção de uma educação que promova uma formação integral dos sujeitos, a adequação do currículo à realidade, interesses e necessidades dos jovens estudantes que ingressam nesta fase do ensino se constitui como importante desafio sob o ponto de vista social (CASTRO, 2017).

$\mathrm{Na}$ esfera das adequações, apesar dos limites ainda enfrentados, sobretudo na oferta de serviços públicos, é possível percebermos ainda que paulatinamente, o avanço no reconhecimento da importância das pessoas com deficiência enquanto sujeitos de direito à educação.

Sob o ponto de vista dos marcos conceituais presentes em declarações e tratados dos quais o Brasil é signatário, vemos em documentos como a Declaração de Salamanca (1994) e a Convenção Interamericana para a Eliminação de Todas as Formas de Discriminação contra as Pessoas Portadoras de Deficiência (BRASIL, 2001), a importância da educação inclusiva como um vetor de redução de desigualdades. Através destes instrumentos, os marcos legais têm compreendido a garantia de condições promotoras de igualdade de acesso, permanência e êxito das pessoas com deficiência à Escola Básica.

Sob a forma da lei, tal avanço é perceptível à medida que a Constituição Federal (Brasil, 1988), a Lei de Diretrizes e Bases da Educação (LDB) 9394/96 (BRASIL, 1996), dentre outros, trazem como prerrogativa o princípio da Educação Inclusiva (EI) como um direito inalienável aos estudantes com deficiências, cabendo aos entes federativos, bem como aos seus respectivos sistemas de ensino, a busca pelos meios necessários à garantia de tal direito.

A EF se constitui, desde a LDB 9394/96, como um componente curricular integrado de maneira obrigatória ao currículo da Educação Básica. Esta situação, por sua vez, trouxe a este componente a superação daquilo que Castellani Filho (1998) aponta como um caráter de 'atividade' presente na LDB anterior. A reboque deste marco legal, esta nova realidade ainda tem ensejado entre professores e professoras da disciplina, a superação do estigma 
historicamente construído acerca da EF na escola: uma disciplina que privilegia aqueles tidos como mais habilidosos e aptos do ponto de vista físico, à mesma medida que exclui grupos como as pessoas com deficiência em suas aulas (ALVES; DUARTE, 2013).

Em nossa prática, esta contradição entre legalidade e a realidade de nossa formação e prática se colocaram à prova quando, no ano de 2017, o Campus Garanhuns do Instituto Federal de Pernambuco (IFPE) recebeu, pela primeira vez, uma estudante com deficiência visual em seu Curso Técnico em Meio Ambiente integrado ao EM.

Naquele contexto, a partir de uma análise conjunta entre o grupo de professores e o Núcleo de Atendimento a Portadores de Necessidades Específicas (NAPNE) do campus, concluíamos que, durante sua formação no Ensino Fundamental, a estudante não teve acesso qualitativamente satisfatório a oportunidades de aprendizagens que a permitissem o desenvolvimento das competências básicos para uma permanência exitosa durante o EM na instituição. Esta realidade nos trouxe o desejo de superar barreiras atitudinais e estruturais que pudessem implicar em dificuldades ao pleno desenvolvimento e aprendizagem da estudante. Esta iniciativa culminou com o desenvolvimento de estratégias metodológicas de natureza interdisciplinar com esta finalidade.

Neste texto, apresentaremos como se deu uma destas estratégias, mediante apresentação do relato de uma experiência interdisciplinar que aproximou as disciplinas EF e EA através do conteúdo Jogos de Tabuleiro.

Metodologicamente, apresentaremos nossa compreensão acerca do jogo enquanto conteúdo e método, compreendendo-o dentro do currículo em movimento interdisciplinar. Em seguida, apontaremos como as os componentes curriculares em um processo de interseção de conhecimentos, desenvolveram os mecanismos necessários à abordagem das temáticas, por meio do jogo.

\section{A IMPORTÂNCIA DO JOGO ENQUANTO CONTEÚDO E INSTRUMENTO NO PROCESSO DE APROXIMAÇÃO INTERDISCIPLINAR}

No clássico livro Homo Ludens, Johan Huizinga (HUIZINGA, 1999) nos apresenta o jogo como uma atividade ou ocupação voluntária que se desenvolve em determinados limites de tempo e espaço tendo como primordial o estabelecimento de regras consentidas entre os seus participantes. O jogo, segundo este mesmo autor, também revela aos seus participantes o desenvolvimento de um sentimento de tensão e alegria que promove um sentimento de fuga à realidade cotidiana que lhe é único.

Ainda que se constitua como um elemento anterior à cultura e à humanidade $^{1}$, o ato de jogar, quando compreendido como uma manifestação

\footnotetext{
${ }^{1} \mathrm{O}$ jogo é fato mais antigo que a cultura, pois esta, mesmo em suas definições menos rigorosas, pressupõe sempre a sociedade humana; mas, os animais não esperaram que os homens os iniciassem na atividade lúdica. É-nos possível afirmar com segurança que a civilização humana não acrescentou característica essencial alguma à idéia geral de jogo. Bastará que observemos os cachorrinhos para constatar que, em suas alegres evoluções, encontram-se presentes todos os elementos essenciais do jogo humano. Convidam-se uns aos outros para brincar mediante um certo ritual de atitudes e gestos. Respeitam a regra que os
} 
da Cultura Corporal (SOARES et al, 2012), reflete muito do que somos enquanto sociedade através do tempo. O jogo, neste contexto, se organiza como um artefato de transmissão cultural, por meio da qual reconhecemos traços que revelam as contradições de nossa territorialidade e temporalidade, assim como, as diferentes compreensões que se expressam nos sentidos, significados e códigos de conduta que cada agrupamento social lega ao sério ato de se divertir.

Quando pensamos o papel do jogo em face de uma abordagem que se pretenda interdisciplinar, reconhecemos seu papel como um instrumento que, em face de uma cultura escolar que fragmenta conhecimentos e os destitui de uma real aproximação com a realidade concreta dos discentes (FREITAS, 1995), aponta para a superação de esteriótipos que legam ao seu uso, a forma de uma recreação desinteressada, um fazer pelo fazer. Em outras palavras, legamos ao seu uso a finalidade de contribuir com uma formação ampliada aos discentes.

Diante deste particular, vemos como essencial apontarmos as possibilidades de criar e recriar o jogo de forma consciente enquanto conteúdo ou estratégia metodológica. $\mathrm{O}$ uso do jogo enquanto método se constitui como uma importante alternativa visando trabalhar a EA no ambiente escolar, seja incluindo-a no currículo, seja através de intervenções. Dentro desse contexto, o jogo é inserido como um instrumento para o desenvolvimento de práticas de EA de forma descontraída e prazerosa (NARCIZO, 2009), aproximando os estudantes da realidade $\mathrm{e}$ incentivando-os a aplicarem o conhecimento adquirido no cotidiano.

No contexto da EF, pensar uma abordagem ampliada do jogo enquanto conteúdo traz como necessidade a sua compreensão como parte integrante da vida do homem, um instrumento que possibilite adentrar no âmbito da forma como os sujeitos da produção do conhecimento - professores e estudantes compreendem e constroem a realidade social da qual fazem parte (SOARES et al, 2012; TAVARES, 2004).

Diante desta exposição, vemos como importante apontarmos como se deu o contexto de produção do conhecimento sobre o tema entre os sujeitos da turma em questão, revelando conjuntura, limites e desafios impostos pela realidade que vivenciamos com a chegada da estudante.

Conforme mencionado anteriormente, o território de desenvolvimento desta experiência foi o IFPE Campus Garanhuns, cidade do Agreste Meridional de Pernambuco situada a $230 \mathrm{~km}$ de distância da cidade de Recife, capital do estado. Inaugurado em 2012, o Campus reflete os limites e avanços angariados pelo processo de expansão dos Institutos Federais em outros contextos, no Brasil (FERREIRA; ANDRADE; SOUZA, 2018). Neste movimento, como em todo processo de expansão e inserção em uma comunidade, a consolidação de uma escola implica a superação de importantes desafios. O primeiro desafio, corresponde à já conhecida questão estrutural.

proíbe morderem, ou pelo menos com violência, a orelha do próximo. Fingem ficar zangados e, o que é mais importante, eles, em tudo isto, experimentam evidentemente imenso prazer e divertimento. (HUIZINGA, 1999 p. 5). 
Como já sabemos, a EF - ainda que não tenha o Esporte como único objeto e razão de ser na Escola - ainda expressa o Ginásio como um de seus principais - quando não o exclusivo - lócus de atuação na Escola. O campus, diante de um cenário de crise orçamentária atravessado pelo nosso país agravada com a imposição da emenda constitucional 45, que estabelece limite nos investimentos públicos - enfrentava já em 2017, graves limites para a implantação de um projeto que contemplasse a construção de um espaço adequado para as aulas.

Com isso, as aulas eram desenvolvidas em ambientes improvisados, cuja seção pelo campus se dava mediante negociação com outros setores em disponibilidade de horários. Neste caso, não eram incomuns, o desenvolvimento de algumas aulas se dar em salas de convivência de funcionários ou mesmo em terrenos pertencentes ao campus e sem as devidas condições para a realização de aulas com a estudante com deficiência, por não apresentarem adequação ergonômica para tal.

Outro ponto importante que compreendíamos como crucial na seara das dificuldades dizia respeito à relevância que os estudantes atribuíam ao papel da EF em sua formação. À época, embora reconhecessem a importância da EF, alguns estudantes não viam relevância em participar das aulas, diante daquilo que os mesmos revelavam como experiências de pouco ou nenhum aprendizado com a EF no ensino fundamental.

Inclusive, havia relatos de estudantes que nunca haviam participado de uma aula de EF, por que nas redes de ensino das quais eles eram estudantes, a EF era tida como uma 'forma de recreação' que acabava por se constituir em prática optativa. No caso da estudante com deficiência visual, a gravidade desta situação se revelava de forma ainda mais nociva, pois, segundo a própria discente, os docentes responsáveis pelo componente curricular durante 0 ensino fundamental não proporcionavam sua participação.

Em um dos momentos, a mesma relatou que enquanto seus colegas participavam regularmente das aulas, ela era levada a uma sala à parte para 0 desenvolvimento de atividades afetas a outros componentes curriculares, contrariando o artigo 26 da LDB, que institui obrigatoriedade à participação na EF como em todas as disciplinas, sendo facultativas apenas as práticas a grupos específicos, como as pessoas com deficiência.

Este afastamento, desenvolvido durante o Ensino Fundamental criou um estranhamento da estudante em relação à EF que se materializava em medo e relutância em participar das aulas. Durante o primeiro semestre, durante a abordagem dos temas Ginástica, Luta e Dança percebia-se que, ainda que ante a disposição e incentivo a criar aulas e atividades que conjugassem experiências sensoriais - como aulas de ginástica laboral, luta e dança adaptada - além da entrega de textos em braile a discente não apresentava segurança suficiente para uma participação efetiva nas aulas.

Frente a esta situação, procuramos construir alternativas geradoras de instrumentos que permitissem com que a estudante pudesse ressiginificar 0 papel da EF em sua formação. Com a chegada do $3^{\circ}$ bimestre, vimos 0 desenvolvimento de tais alternativas ganhar corpo, quando avaliamos a possibilidade do desenvolvimento de ações metodológicas de cunho 
interdisciplinar, mediante integração entre as disciplinas de educação física e EA, durante a abordagem do tema Jogo.

$\mathrm{Na} E F$, o jogo foi tratado, à luz da abordagem crítico superadora, como uma prática produzida e sistematizada pelo ser humano através dos tempos com as mais diversas intencionalidades, o que a tornaria passível de uso, inclusive enquanto estratégia, no contexto do ensino sobre questões ambientais.

A partir do recorte escolhido, estabelecemos os seguintes objetivos de aprendizagens para os estudantes:

$\checkmark$ Objetivo geral: aprender sobre as diferentes tipologias de jogo, visando reconhecer a especificidade do jogo enquanto conteúdo da Cultura Corporal, passível de modificações e tematizações, proporcionando aos jogadores a oportunidade de aprender sobre questões ambientais e sobre o papel da inclusão no jogo.

$\checkmark$ Objetivo específico: os estudantes deveriam aprender a desenvolver jogos educacionais que tivessem a inclusão como princípio básico, não apenas diante das necessidades apresentadas pela colega de turma, mas diante do fato de que vivemos numa sociedade plural, na qual pessoas apresentam necessidades que precisam ser entendidas como direitos básicos e essenciais para uma existência digna.

No que diz respeito aos recortes temáticos, selecionamos os jogos populares e de salão, com o intuito de proporcionar aos discentes, um olhar ampliado acerca dos limites e possibilidades de seu uso enquanto estratégia de ensino e aprendizagem sobre temas ambientais e sobre a inclusão. Em educação física, os estudantes foram instrumentalizados acerca das diferentes tipologias de jogo, suas particularidades e usos enquanto práticas corporais na sociedade.

Quadro A: relação dos conteúdos que se aproximaram nos componentes curriculares EF e EA na ação interdisciplinar.

\begin{tabular}{|c|c|}
\hline Componente Curricular & \multicolumn{2}{|c|}{ Bloco de conteúdos } \\
\hline \multirow{2}{*}{ EDUCAÇÃO FÍSICA } & $\checkmark \begin{array}{l}\text { Jogo Popular: queimado, } \\
\text { barra/pique bandeira. }\end{array}$ \\
& $\checkmark \begin{array}{l}\text { Jogo de Salão/Tabuleiro: damas, } \\
\text { jogo da velha, jogos carteados, } \\
\text { trilhas, ludo. }\end{array}$ \\
\hline EDUCAÇÃO AMBIENTAL & $\checkmark$ As características e o papel do \\
educador ambiental. \\
$\checkmark \checkmark$ Estratégias de Educação Ambiental: \\
Jogos, músicas, palestras, oficinas, \\
visitas, técnicas, entre outras.
\end{tabular}

Fonte: Elaboração própria 
A proposta do componente curricular EA se baseou em auxiliar 0 estudante no desenvolvimento de competências e habilidades para estarem atuando como educadores ambientais. Os estudantes aprenderam sobre as questões ambientais presentes no seu cotidiano, desde o seu primeiro ambiente, ou seja, na sua residência, na sua escola, até escalas globais.

Inserido nessa abordagem, na primeira unidade foram apresentados alguns problemas ambientais relacionados a poluição atmosférica, a poluição hídrica e a poluição do solo. Já na terceira unidade, foi dado o enfoque para as estratégias metodológicas de EA. Conceitos como o perfil do educador, as estratégias e educação em Meio Ambiente e a importância da sensibilização de todos à elaboração de materiais didáticos acessíveis aos diversos tipos de deficiência.

A utilização do jogo se constituiu como ponto de interseção das unidades a partir da necessidade de utilizar os conhecimentos adquiridos nas unidades anteriores para elaboração dos jogos enquanto estratégia de sensibilização dos outros estudantes.

A intencionalidade pedagógica da abordagem desenvolvida teve como premissa, não apenas a criação de um ambiente inclusivo para a discente, mas o reconhecimento dos demais acerca da importância de concebermos uma sociedade na qual possamos perceber o nosso papel na garantia dos direitos sociais das pessoas com deficiência.

Esta situação se consolidou em momentos como durante a abordagem do conteúdo Pique/Barra Bandeira, quando criamos instrumentos para a participação da discente, por meio de um sistema de parcerias, onde os colegas, de mãos dadas, criavam condições para que cada um pudesse, em algum momento, auxiliar a colega a melhor participar das brincadeiras desenvolvidas. Noutro momento, experimentamos que todos jogassem em duplas, estando um colega de mãos vendadas enquanto outro se propunha a ser seu guia na brincadeira.

$\mathrm{Na}$ abordagem do conteúdo jogos de tabuleiro, o docente de EF adaptou jogos da velha, trilhas e ludos em alto relevo, para que a estudante pudesse participar efetivamente das aulas. Em EF, eles aprenderam acerca do histórico, mecânica e regras destes jogos. Uma vez instrumentalizados acerca dos conteúdos, os estudantes, em EA foram estimulados a refletirem sobre os problemas ambientais vivenciados no componente curricular e escolherem sobre qual deles gostariam de construir algum tipo de jogo. Além disso, foram instruídos a escolherem um tema com o qual haviam se identificado e que achavam de grande relevância para repassar aos colegas.

Outro ponto importante foi sobre os elementos que seriam utilizados na construção do jogo para permitir a inclusão das pessoas com deficiência visual. Nessa etapa, a participação da estudante com deficiência visual foi muito importante, pois viabilizou aos demais estudantes entender que elementos precisam se fazer presentes para facilitar comunicação através dos jogos. Em seguida, os professores dos componentes curriculares atuaram apoiando a elaboração dos jogos com a inserção e ajustes de conteúdo. Dessa forma, a construção dos jogos ocorreu de forma participativa, abrangente, dinâmica e 
contextualizada envolvendo, assim, diversas características da EA de maneira aproximada da discussão do Jogo no contexto da EF.

Considerando a particularidade da ação desenvolvida, a avaliação da unidade foi pensada junto aos estudantes. Partindo da compreensão do ato de avaliar como um processo que supera a lógica do exame (LUCKESI, 2008) em prol de um movimento dialógico. Neste contexto, utilizamos os seminários interativos, tempo pedagógico em que os processos de ensino-aprendizagem podem ser sistematizados sobre a forma de relatórios e exposições que privilegiam a reflexão e socialização do conhecimento acumulado durante as disciplinas com a comunidade escolar (TAFFAREL; ESCOBAR; FRANÇA, 1995).

O evento escolhido para a apresentação das produções dos estudantes foi a 14a Semana Nacional de Ciência e Tecnologia (SNCT) 2017, evento de abrangência nacional promovido pelo ministério da Ciência, Tecnologia Inovação e Comunicação que engloba dentre outros órgãos, os Institutos Federais enquanto espaço de sua realização. Na SNCT 2017, os estudantes da turma promoveram vivências sensoriais com os jogos de Ludo e Trilha temáticos adaptados, nas quais os estudantes dos cursos técnicos de meio ambiente e outros cursos sentiam como um portador de deficiencia visual percebia os jogos produzidos.

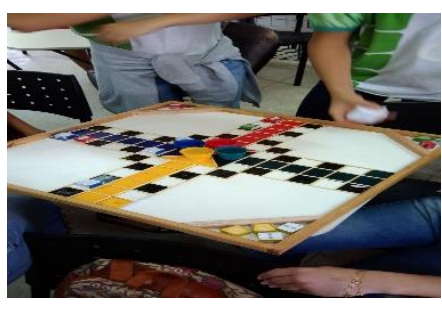

Figura A: Produção de jogos de ludo sobre materiais recicláveis em alto relevo, com dados em braile, em sala de aula.

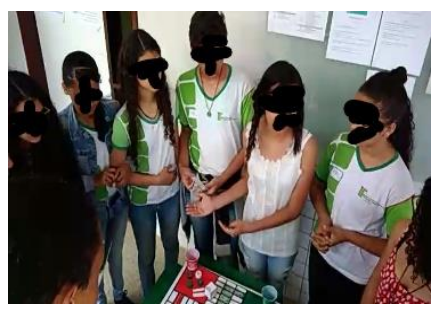

Figura B: Explicação do jogo produzido pelo grupo da discente deficiente visual durante a SNCT 2017.

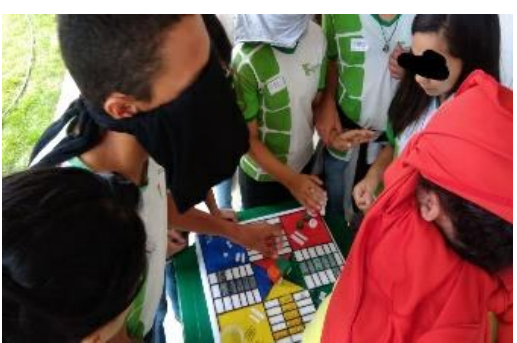

Figura C: vivência, por alguns estudantes, do ludo sensorial desenvolvido pelo grupo da estudante com deficiência.

As atividades desenvolvidas foram muito bem recebidas pela comunidade escolar, diante de sua repercussão para uma formação humanizada de todos. Esta compreensão, inclusive, se fez presente na análise da estudante acerca da ação: "Infelizmente aí fora não se tem a consciência para fazer coisas acessíveis para todos. Com essa ação, não só eu aprendo mas meus amigos de sala de aula também. Se lá na frente eles encontrarem uma pessoa com deficiência vão saber como lidar" (IFPE, 2017). 


\section{CONSIDERAÇÕES FINAIS}

A partir do relato apresentado, concluímos que a abordagem dos temas ambientais mediante aproximação entre as disciplinas EF e EA foi uma experiência exitosa, pois levou os estudantes a perceberem como a discussão ambiental perpassa pelos diversos componentes curriculares. Atividades como essa são desafiadoras por permitirem aos docentes e discentes, a oportunidade de ampliar o repertório de conhecimentos, estabelecendo conexões entre temas e abordagens.

Também reconhecemos que a construção deste tipo de jogo ambiental se constituiu como uma proposta que trouxe à tona a abordagem de temas salutares para formação dos estudantes enquanto cidadãos. Temas esses que, por vezes, são negligenciados nas instituições de ensino ou abordados de forma superficial e descontextualizada, privando o estudante de um processo formativo mais amplo.

A construção de novos valores através da EA busca redefinir não apenas a relação do ser humano com a natureza, mas também, a relação entre os indivíduos e a sua relação consigo mesmo. E a escola é um espaço importante de convivência e crescimento onde crianças e adolescentes adquirem valores fundamentais em uma das fases formativas mais importantes da sua vida, sendo assim, é o lugar ideal para o desenvolvimento de programas de EA.

Em muitos momentos, as idiossincrasias inerentes ao fazer pedagógico nos levam a desconsiderar a importância do desenvolvimento de ações conjuntas nos moldes que apresentamos neste relato. Ainda assim, reiteramos a importância de superarmos estes limites, através do desenvolvimento de ações que reflitam os princípios e a função social da Rede Federal de Educação Tecnológica: a busca por uma educação cidadã, de perspectiva interdisciplinar, com consistente base teórico-metodológica, comprometida com um desenvolvimento sustentável e sensível aos anseios das camadas historicamente marginalizadas por nossa sociedade. Dentre estas, as pessoas com deficiência.

\section{REFERÊNCIAS}

ALVES, M. L. T; DUARTE, E. A exclusão nas aulas de Educação Física: fatores associados com participação de alunos com deficiência. Movimento. Porto Alegre, v. 19, n. 01, p. 117-137, jan/mar de 2013.

BRASIL. Constituição da República Federativa do Brasil de 1988. Disponível em http://www.planalto.gov.br/ccivil 03/constituicao/constituicao.htm. Acessado em 29/08/2019

BRASIL. Lei no 9.795 de 27 de Abril de 1999. Dispõe sobre a educação ambiental, institui a Política Nacional de Educação Ambiental e dá outras providências. Disponível em. $<$ http://www.planalto.gov.br/ccivil 03/leis/19795.htm>. Acessado em 25/08/2019 
BRASIL. Decreto no 3.956, de 8 de outubro de 2001. Promulga a Convenção Interamericana para a Eliminação de Todas as Formas de Discriminação contra as Pessoas Portadoras de Deficiência. Disponível em: http://www.planalto.gov.br/ccivil 03/decreto/2001/d3956.htm acessado em 29/08/2019.

BRASIL. Lei no 9.394, de 20 de dezembro de 1996 (LDBEN). Dispõe sobre as Diretrizes da Educação Básica. Brasília, 1996. Disponível em: http://www. planalto.gov.br/ccivil_03/leis/19394. htm - acesso em 26/08/2019.

CASTRO, V.C. e. As atribuições da Educação Física escolar: um enfoque especial no Ensino Médio. Motrivivência, Florianópolis, v. 29, n. 52, p. 124135, set. 2017.

CARVALHO, I. C. M. Educação Ambiental: a formação do sujeito ecológico. São Paulo: Cortez, 2006.

CASTELLANI FILHO, L. Política Educacional e Educação Física. Campinas: Autores Associados, 1998.

DECLARAÇÃO DE SALAMANCA: Sobre princípios, políticas e práticas na área das necessidades educativas especiais. Salamanca - Espanha, 1994. Disponível em http://portal.mec.gov.br/seesp/arquivos/pdf/salamanca.pdf. Acessado em 20/08/2019.

FERREIRA, S. L.; ANDRADE, A.; SOUZA, F. E. C. Reflexões sobre a expansão dos Institutos Federais no estado de São Paulo. Jornal de Políticas Educacionais. V. 12, n. 2 . Janeiro de 2018

FREITAS, L. C. A REFORMA EMPRESARIAL DA EDUCAÇÃO: nova direita, velhas ideias. São Paulo: Expressão popular, 2018.

FREITAS, L. C. Crítica da Organização do Trabalho pedagógico e da didática. Campinas, SP: Papirus, 1995.

HUIZINGA, J. Homo ludens: o jogo como elemento da cultura. São Paulo, SP:. Perspectiva, 1999.

INSTITUTO FEDERAL DE PERNAMBUCO. Exposições na pauta do segundo dia da SNCT. ifpe.edu.br, 2017. Disponível em http://www.ifpe.edu.br/campus/garanhuns/noticias/exposicoes-na-pauta-dosegundo-dia-da-snct. Acesso em 11/08/2019

LORIELI, M. A. Filosofia: fundamentos e métodos. São Paulo: Cortez, 2002.

LUCKESI, C. Avaliação da aprendizagem escolar: estudos e proposições. São Paulo: Cortez; 2008

NARCIZO, K. R. S. Uma análise sobre a importância da de trabalhar Educação Ambiental nas escolas. Revista Eletrônica do Mestrado em Educação Ambiental. Vol. 22. p. $86-94$.

PELICIONE, M. C. F. Educação Ambiental para uma Escola Sustentável. In: PHILIPPI JR, A.; PELICIONE, M. C. F. (Eds.) Educação Ambiental e Sustentabilidade. São Paulo: Manole, 2005.

PORTO-GONÇALVES, Carlos Walter. A globalização da natureza e a natureza da globalização. Rio de Janeiro: Civilização Brasileira, 2006 
SAVIANI, D. Pedagogia Historico-Critica: primeiras aproximações. Campinas: Autores Associados, 2011

SOARES et al.. Metodologia do Ensino da Educação Física. São Paulo: $2^{\underline{a}}$ ed. Cortez, 2012.

TAFFAREL, C. N. Z.; ESCOBAR, M. O.; FRANÇA, T. L. Organização do tempo pedagógico para a construção. Estruturação do conhecimento na área de Educação

Física e esporte. Motrivivência, Florianópolis, n. 8, p. 124-133, jan. 1995

TAVARES, M. O ENSINO DO JOGO NA ESCOLA: uma abordagem metodológica para a prática pedagógica dos professores de Educação Física. Recife: Edupe, 2004

CERVO, A. L.; BERVIAN, P. A.; SILVA, R. da. Metodologia científica. 6. ed. São Paulo: Pearson Prentice Hall, 2007.

KENSKI, V. M. Tecnologias e ensino presencial e a distância. Campinas, SP: Papirus, 2003.

PACHECO, E. M.; MORIGI, V. (Org.). Ensino Técnico, Formação Profissional e Cidadania: a revolução da Educação Profissional e Tecnológica no Brasil. Porto Alegre: Tekne, 2012. 